\title{
THE EVALUATION OF ONE PUBLIC NURSING COLLEGE IN TERMS OF THE PROGRAMME CRITERIA OF THE HIGHER EDUCATION QUALITY COMMITTEE.
}

\author{
MM Mulder, University of the Free State \\ LR Uys, University of KwaZulu-Natal
}

\begin{abstract}
The purpose of the study was to do an evaluation of the KwaZulu-Natal College of Nursing against the seven input criteria of the Higher Education Quality Committee and make recommendations about improvements necessary in order for the College to become accredited with this body.

The evaluation was based on a survey of all teaching sites of the Nursing College, involving an architect and nurse educators. Questionnaires, interviews and site inspection check lists were developed and used to collect data. An initial data summary was done by the team leader, and this was first discussed with the evaluation team and then validated in a meeting with the College staff.

The results addressed each of the seven criteria and it was found that only one (assessment) was met, while three were partially met and three not met. It became evident that $70-80 \%$ of the KZN CN budget is spent on salaries of staff and students. The implication is that a minimal percentage could have been spent on teaching and learning.

South African Colleges of Nursing will never be able to adhere to the standards of higher education, except if the governance context changes to favour the autonomy of these colleges. The biggest challenge lies in adequate funding to ensure quality standards within the college teaching and learning environment, although system development and adequate facilities are also serious limitations.
\end{abstract}

Keywords: Higher Education Quality Committee; programme accreditation; nursing college; institutional evaluation

\section{Acknowledgement}

The input of the staff of the KZN College of Nursing, Ms Margaret Bass (librarian at UKZN) and Mr Sphiwe Mthetwa (Architect at Paton Taylor Architects), Prof Janse Tolmie (IntactSoft) and all the field workers is much appreciated.

\section{Introduction}

The Higher Education Quality Committee (HEQC), a permanent sub-committee of the Council of Higher Education ( $\mathrm{CHE}$ ), has set criteria for programme accreditation in higher education. Without this accreditation, programmes may not be offered in the Higher Education (HE) sector in South Africa. 
These criteria (CHE 2004:1-33) should drive programme development of the new proposed nursing qualifications set by the South African Nursing Council (SANC 2013a). Geyer (2008: 87) states that in the health professional education sector in South Africa, it is only nursing colleges and hospital schools that find themselves outside the education mainstream in an environment with a very different mission, yet they are obliged to comply with national education standards. These nursing training institutions fall within the jurisdiction of the provincial department of health.

It is essential for nursing colleges to apply for accreditation of their programmes with the Higher Education Quality Committee (HEQC) to ensure continuation of their existence. This Committee does not accredit institutions, but only programmes. All the new nursing qualifications (see table 8.1) are pegged on the Higher Education Qualifications Sub-Framework Draft (HEQSF) (CHE 2013: 38; FUNDISA 2011; SANC 2013a) within the higher education sector as classified by the NQF Act 67 of 2008 (RSA 2008).

Table 8.1: Qualification types on the HEQSF and correlating SANC categories (CHE 2013:38; FUNDISA 2011)

\begin{tabular}{|l|l|l|}
\hline Undergraduate qualifications & Exit level & SANC category \\
\hline Higher Certificate & 5 & Registered Auxiliary Nurse \\
\hline Advanced Certificate & 6 & \\
\hline Diploma & 6 & Registered Staff Nurse \\
\hline Advanced Diploma & 7 & Registered Midwife \\
\hline Bachelor's Degree & 7 or 8 & Registered Professional Nurse and Midwife \\
\hline Postgraduate qualifications & & \\
\hline Postgraduate Diploma & 8 & Proposed Specialist Nurse \\
\hline Bachelor Honours' Degree & 8 & \\
\hline Master's Degree & 9 & Proposed Advanced Specialist Nurse \\
\hline Doctoral Degree & 10 & \\
\hline
\end{tabular}

The CHE (2004: 2) use a set of 19 criteria to evaluate a programme, of which 8 are input criteria, 7 are process criteria, and the remaining 3 are output criteria. The first phase of the programme accreditation process is the candidacy phase (CHE 2004: 4). During this phase an institution has to demonstrate that it meets the input criteria or that it has the potential or capability to meet these criteria within a stipulated period of time. The institution's application should be based on a critical self-evaluation of the new programme against requirements of the HEQC programme input criteria. The institution should also submit a plan for the implementation of the new programme specifying implementation steps including time frames, resources and strategies to meet process, output and impact criteria.

Quality-related criteria such as the CHE input criteria for new programmes act as evaluative tools for accreditation activities and set broad benchmarks for quality management. Higher education institutions utilize these criteria to reflect on their quality management arrangements and to guide the production of self-evaluation reports (CHE 2004: 8).

FUNDISA assisted the KwaZulu-Natal College of Nursing (KZN CN) with a feasibility study to prepare itself for the development of new programmes through the process of evaluation and analysis. This process 
was based on an extensive research investigation and resulted in a self-evaluation report and recommendations to guide the quality of the new planned programme development initiative of KZN $\mathrm{CN}$.

\section{Purpose of the feasibility study}

The purpose of the feasibility study resulted in an application process of the KZN CN to have their programmes accredited by the HEQC.

The application for accreditation of a programme focuses only on the input criteria, and that is what the feasibility study has therefore addressed. The objectives of the feasibility study in order to meet the CHE requirements were to undertake what was, in essence, a self-evaluation of the KZN CN against the seven input criteria of the HEQC and to make recommendations about necessary improvements.

\section{The process followed}

A team consisting of various experts, including a nursing academic and an architect, conducted the visits to all the teaching sites. The architect inspected the physical facilities while the nursing academic conducted interviews and evaluated teaching resources. Then a management information expert and two nurse educators visited the central office of the college. Three campuses were visited by an academic librarian. During the site visits, groups of academics, support staff and students were interviewed, as well as the CEO and Chief Nurse Manager of an affiliated hospital. This study was done over an intensive four-month period, with a team of university academics and an architectural firm. The extensive consultation process, repeated feedback-loops and the $100 \%$ sample in terms of campuses used for data collection made it a valid and reliable process.

To interpret the data, an analysis was done through a workshop with experts, during which the information gathered from the sites were compared with the criteria set by the Higher Education Quality Committee and a rating were decided upon by the group. An attempt was made to address all the standards set by the HEQC under each input criterion (CHE 2004: 4-7). Criterion 8 was excluded from the feasibility study as it referred to postgraduate procedures which are beyond the scope of the college sector.

The report was presented to the College at a face-to-face meeting and in writing.

\section{Results and recommendations for each criterion}

Five input criteria were partially met and three were not met at all. As a result, all criteria need serious attention in order for the college programmes to be accredited with the $\mathrm{CHE}$, especially the teaching and learning strategy (criterion 4), student assessment policies and procedures (criterion 5) and programme administrative services (criterion 7).

Criterion 1: Programme design: The programme is consonant with the institution`s mission, forms part of institutional planning and resource allocation, meets national requirements, the needs of students and other stakeholders, and is intellectually credible, It is designed coherently and articulates well with other relevant programmes, where possible. 
Evaluation: Partially met.

The study focused on the programmes the College plans to offer in the new SANC Qualifications Framework. Stakeholders expressed the need for both professional nurses and new staff nurses, and voiced their dissatisfaction with the auxiliary nurses produced in the private sector. In discussion with the College management, an outline of the programmes they planned to produce at each campus was provided, and the teaching sites and hospital management specified. However, the authors of this chapter made an alternative proposal that would:

- $\quad$ Provide for a slight increase in the production of nurses in this province;

- Maintain the number of professional nurses produced by the College;

- Provide at least as many nurses with midwifery training as are currently trained;

- Set a target for the production of staff nurses that is slightly higher than the enrolled nurses currently produced;

- Increase the number of auxiliary nurses trained.

One curriculum (midwifery) was evaluated in depth and it was found that the balance between theory, practice and experiential learning was not satisfactory. Hospital stakeholders also commented on poor curriculum content in terms of relevance. They felt that experiential learning was negatively affected by low numbers of professional nurses in clinical settings and very few clinical preceptors. The college develops its own Learner Guides for programmes, study guides for specific courses, as well as workbooks. The Learner Information Guide and Rules generally provides information about the College (philosophy, governance, and regulations which include examination rules and student discipline, etc.), and general information (registration with the SANC, leave, language, etc.). The College does not publish a single formal "College Prospectus" or College Handbook" which includes all academic information. Programme details are not provided in the same publication.

The workbooks often focus on only one or a few competencies or assignments. They provide clear guidance about expectations, and often also assessment criteria. However, the question arises as to how the rest of the work-based learning is structured and directed.

\section{Recommendations}

1.1 Review mission and vision:

- $\quad$ Align with new proposed clinical model in SA

- $\quad$ Address research and community engagement

1.2 Perform a situation analysis for programme accreditation (establish need for each nursing qualification)

1.3 Standardize and publish rules in a College Handbook

1.4 Design comprehensive module guides to:

- $\quad$ direct student learning

- $\quad$ promote integration of nursing theory and practice

1.5 Increase student numbers per qualification to be cost effective

1.6 Increase auxiliary nurse intake and place in clinics

1.7 Promote a Positive Practice Environment (PPE)

1.8 Ensure intellectual credibility of clinical experience in terms of competencies and learning outcomes 
1.9 Clarify and select theoretical clinical teaching and learning models:

- $\quad$ E.g. mentoring, reflective practice

- $\quad$ Prepare policies and staff for these approaches

1.10 Ensure continuous assessment to prepare competent students

1.11 Focus on professionalism and caring in the new curricula

Criterion 2: Student recruitment, admission and selection: Recruitment documentation informs potential students of the programme accurately and comprehensively, and admission adheres to current legislation. Admission and selection of students are commensurate with the programme's academic requirements, within a framework of widened access and equity. The number of students selected takes into account the programme's intended learning outcomes, its capacity to offer good quality education and the needs of the particular profession (in the case of professional and vocational programmes).

Evaluation: Partially met.

The College has a bursary system, with the provincial DOH providing 640 bursaries for 4-year diploma students, 548 for enrolled nursing students and 48 for auxiliary nursing students. This is clearly a great incentive for students, since it is a very substantial bursary. However, it does restrict recruitment, since the College does not take any students for whom they do not have bursaries.

Two forms of selection are currently involved:

1. Central application and selection is done for the R425 and for R683. Students apply centrally online and the process is managed by a unit in the $\mathrm{DOH}$, based on criteria set by the College. This system is run by staff appointed for the period of selection only, and the campus principals are heavily involved. Since the College does not have staff for this function, it demands much involvement from the principals, and the quality is questionable, since contract workers are involved.

2. District-based selection is done for most of the other programmes. The health facilities in a district nominate the people they want on the programme, a selection is made at the district level, and the school is informed who will be coming.

The selection criteria adhere to legislation, but do not seem to refer to the new grade 12 changes. Only students from KZN province are selected. If the College is part of the higher education system, which serves the national interest, this is not acceptable. Some staff also indicated that although there are selection criteria and processes, these are all ignored on occasion when a "premier's list" is presented to them of candidates they have to take.

Many campuses are placed in rural areas and train mainly African females. While they do not have specific equity policies for selection, they are targeting a disadvantaged group in the community. The KZN CN should be given credit for the access they provide to rural women (and men) to further their education.

\section{Recommendations:}

2.1 Promote access for students from the rest of the country

2.2 Select students based on equity plan to promote diversity

2.3 Develop and adopt a selection policy 
Criterion 3: Staffing: Academic staff responsible for the programme are suitably qualified and have sufficient relevant experience and teaching competence, and their assessment competence and research profiles are adequate for the nature and level of the programme. The institution and/or other recognised agencies contracted by the institution provide opportunities for academic staff to enhance their competences and to support their professional growth and development.

Evaluation: Partially met.

The level of academic qualifications of academics and the positions in which they are employed is summarized in table 3.6. About $9 \%$ of the academics are in management positions and a further $16 \%$ are in senior positions. The bulk of the academics are lecturers or junior lecturers. This might place quite a heavy load of academic leadership on about $25 \%$ of the total staff. This could be problematic in a period of radical change such as the College is facing now.

According to one of the KZN CN documents, the College currently has a total of 576 posts, of which 485 are filled, giving a vacancy rate of $16 \%$. The College identified the inability to recruit and retain academic staff in rural areas as one of its weaknesses.

A total of $23 \%$ of academics have Honours' degrees or above, which will be the requirement for offering a B-degree, and this is no better on the main campuses. The vast majority of academics have B degrees (59\%). Since the percentage of Senior Lecturers and above is $25 \%$, it would seem that all the seniors have an Honours' degree or higher. This has serious implications for teaching, since it means that most of the instruction is done by B-qualified academics.

Some of the hospital managers believe that the qualifications and attitudes of nurse educators should be improved in order to improve the quality of nursing education. They also point out that sometimes educators are so busy improving their own qualifications that they pay scant attention to the needs of the students.

The average number of years teaching experience of academics is 10 years, with the minimum being1 year and the maximum 24 years. There seems to be little difference between campuses and subcampuses, with the average maximum being two years less on sub-campuses, and everything else being the same.

No data was obtained about professional experience, but about $34 \%$ of the academics have a specialist qualification in an area of nursing. Most of these academics work on the campuses, but the Primary Health Care qualification is also found on a number of sub-campuses, although only one of them offers this qualification. $78 \%$ of academics have had assessor training and $20 \%$ have had moderator training. The moderation level will have to be improved if the College becomes independent of the universities with which it is currently associated for quality control.

A total of 71 academics (19\%) were involved in research, of which $55 \%$ related to formal studies. This is a good foundation on which to build future research involvement of the College.

The College makes use of the Induction Policy of the Department of Health. While this is generally a good document, it does not provide detail specific to the role of an educator and how an educator should be inducted.

\section{Recommendations:}

3.1 Motivate academics to do Master's degrees

3.2 Train more moderators 
3.3 Develop and implement an induction policy procedure

3.4 Implement recommendations of the National Nursing Research Strategy

3.5 Aim at a more realistic staff to student ratio, such as $15: 1$ to 20:1, by:

- $\quad$ either increasing student numbers, or

- $\quad$ redeploying educators and changing teaching strategies

3.6 Develop and populate a new support staff establishment if the financial and human resource management system changes

3.7 Create a new academic staff establishment that includes a range of disciplines to offer the Bdegree

3.8 Develop and implement a performance management system

3.9 Increase exposure of staff to regional and national educational events.

Criterion 4: Staffing: The academic and support staff complement is of the correct size and seniority for the nature and field of the programme and the size of the student body to ensure that all activities related to the programme can be carried out effectively. The ratio of full-time to part-time staff is appropriate. The recruitment and employment of staff follows relevant legislation and appropriate administrative procedures, including redress and equity considerations. Support staff are adequately qualified and their knowledge and skills are regularly updated.

Evaluation: Criterion not met

The academic to student ratio is 12: 1 on average, with little variation between sub-campuses (13:1) and campuses (12:1). This is a liberal ratio when compared with the more common 20: 1 at universities and 30:1 at Universities of Technology. While the College indicated that they had enough staff in their own SWOT analysis, many of the hospital managers felt that more staff were needed. The perception of inadequate staff in the presence of such ratios might be related to the repeated intakes of small groups, the teaching of which keeps academics very busy. Almost all academic staff are permanent employees, with only one person on contract and two people employed part-time.

The financial and human resource management of the College is mainly done by staff outside the College. In the case of the Central College office, the work is done at the provincial DOH offices, and in the case of the campuses and schools, the hospital to which they are attached manages these functions. They sometimes have one clerk to assist them with entering data or keeping records, but the bulk of the work is done outside the college.

The recruitment and selection of all staff, including academics, is based on the policy of the DOH. This has a range of limitations in the sense that it does not allow for adequate shaping of these processes to achieve the goals of the educational institution. For instance, the composition of the selection committees does not stipulate the involvement of students and a standardized interview guide is compulsory, which makes it difficult to follow up on aspects of the CV, a process vital to appointing an academic. When numerous candidates qualify for the position in terms of requirements, additional advantages may not be used for short-listing. These are just a few of the issues which make it important to develop a policy aimed at appointing the best possible academics. 
It is difficult to believe that a great diversity of ideas and approaches is present in the light of the fact that all academics are from one discipline (nursing) and many of them have lived, and were educated in, the region.

Even with these enviable academic to student ratios, none of the campuses have allocated a permanent academic to their simulation laboratory so that learning in this setting can be open to students at all times. Allocation of staff to functions seems to be rather traditional, and the deployment and utilization of staff should be redesigned to make better provision for newer models of teaching.

Currently, the College employs only nurse educators who teach all subjects; for example, physiology, anatomy, sociology and psychology. This will no longer be acceptable if the College offers a B degree, since the academics teaching these subjects will have to have at least Honours' or Master's degrees in these subjects (and not in nursing). Opening up the staff establishment for academics from other disciplines will go a long way to improving diversity.

Since most of the financial and human resource management is done outside the campus, it is not surprising that most of the support staff have limited qualifications. A total of $42 \%$ have less than matric and only $8 \%$ have a post-matric certificate. While this may be adequate for their current functioning, it will be totally insufficient if the College takes over its own financial and human resource management. Most of them are employed as orderlies, and only $12 \%$ are in senior positions. On average, here is only 1 support staff member for every 3 academics. On sub campuses the ratio is much lower, with a support staff member for every 2 academics, while on campuses it is closer to 1 to 4 . The reasons for such a difference are difficult to identify.

\section{Recommendations:}

4.1 A more realistic staff to student ratio, such as $15: 1$ to $20: 1$, should be aimed at by either increasing students or by redeploying educators and changing teaching strategies.

4.2 If the financial and human resource management system changes, a new support staff establishment will have to be developed and populated.

4.3 At campuses planning to offer the B-degree, a new academic staff establishment will have to be created to address the need for academics from a range of disciplines.

Criterion 5: Teaching and learning strategy: The institution gives recognition to the importance of promoting student learning. The teaching and learning strategy is appropriate for the institutional type (as reflected in its mission), mode(s) of delivery and student composition, contains mechanisms to ensure the appropriateness of teaching and learning methods, and makes provision for staff to upgrade their modes of instruction. The strategy sets targets, plans for implementation, and mechanisms to monitor progress, evaluate impact and effect improvement.

Evaluation: Criterion not met.

No teaching and learning strategy or policy exists. On each campus or school a sub-campus Academic Board exists, which has the responsibility to "supervise all academic matters". However, it looks as though teaching and learning approaches are informally decided and implemented.

The College does not have a designated Academic Development unit or staff. This function is to some extent shared by the Central Office and the Principals of campuses. In general, these academic 
managers are well qualified in terms of academic qualifications, but their competence with regard to Academic Development may be limited.

With regard to student development, it seems that no specific initiatives exist. Students do have a Student Representative Council and are represented on Senate and Council but not on campus boards. The Learner Guides make no mention of the organized student body, and do not refer to any specific student developmental options. No foundational courses are available, and neither is there targeted capacity building such as the development of computer, reading or learning skills. The curricula show no sign of specific capacity building for students as part of the courses or modules.

For counselling of students, the class teacher or the Employee Assistance Programme (EAP) of the hospital is used.

With regard to the balance of teaching approaches, the larger campuses tend to use a greater mix of teaching and learning strategies, while smaller sub-campuses are still mainly using lecture methods and limited demonstrations. This may be related to the inadequate staff and facilities. For instance, where no adequate library or computer-based resources are available, or the book collection is locked away because there is no librarian, students of necessity become dependent learners.

It seems that clinical skills' and anatomy laboratories are generally still used only during classroom time, and are rarely accessible to students outside these times. On the one hand, this is because students are kept busy in a school-like timetable for the whole day during their block periods and, on the other, because these facilities are not accessible after working hours or over weekends. This severely limits their value to students and the development of independent learners.

Academics from 6 campuses attended conferences over the last two years, and on only 13 campuses were short courses made available for continuing education. On the majority of campuses, academics rely on formal studies to upgrade their knowledge and skills.

Students are provided with course guides which outline the components of the course. Objectives, content and learning experiences are listed, but in some cases learning resources, assessment strategies and a time schedule are not part of the guide. This leaves the student with some gaps in understanding the teaching and learning programme.

Students are sometimes requested to evaluate courses, but there is no formal system and no easy way to do this anonymously. Suggestion boxes are also used. No formal way exists to identify good teachers.

\section{Recommendations:}

5.1 Develop a teaching and learning strategy based on a thorough needs analysis of the target group of students

5.2 Develop a financial strategy guided by good governance principles to fit the resources of the college

5.3 Create a vibrant learning environment by establishing an Academic Development Unit inclusive of educational specialists and educational psychologists

5.4 Enrich new curricula by including Information Technology, English and Numeric Literacy

5.5 Network with universities to explore how the following divisions function:

- $\quad$ Academic support

- $\quad$ Libraries

- $\quad$ Financial management 
- Information Management

- Human Resources.

Criterion 6: Student assessment policies and procedures: The different modes of delivery of the programme have appropriate policies and procedures for internal assessment; internal and external moderation; monitoring of student progress; explicitness, validity and reliability of assessment practices; recording of assessment results; settling of disputes; the rigour and security of the assessment system; RPL; and for the development of staff competence in assessment.

\section{Evaluation:}

Student assessment is clearly a strong feature of all the programmes. The "Examination and Evaluation Rules" refer to on-going theoretical and clinical evaluations in a variety of formats (formative testing). The Duly Performed System, which governs entry to the examination, requires an average of $50 \%$ in what is probably meant to be formative testing (but says summative testing). It also provides for both clinical and written examinations.

The information about assessment is reflected in the "Learner Information Guides" which are produced for each programme and of which each student receives a copy. The assessment policy outlines ongoing theoretical and clinical evaluations, written and clinical examinations, the process of examination and re-marking policy. This is a college-wide policy applicable to all students.

In some course guides, e.g. "Ethos and Professional Practice", assessment is referred to by listing assessment criteria for knowledge and skills. However, in no course outline is an assessment listed as one of the teaching and learning strategies. In none of them are assignments outlined, or assessment criteria for such assignments provided. In one, dates of tests are provided, although this might be done as part of the block programmes. No reference is made to turn-around times of formative assessments. The following additional policies exist:

- $\quad$ Procedure to be followed when a learner is found cheating;

- Procedure to be taken before written examinations;

- Instructions to invigilators;

- Instructions to OSCE organiser;

- Guidelines for compiling clinical nursing science examinations.

A series of more detailed forms and instructions indicate attention to detail in this component of the work of the College. The College has an RPL policy, but it is quite old and not actually in use.

The KZN CN has no moderation policy, but does have procedural guidelines formulated by the college that the university uses during moderation. Academic staff who teach a course are responsible for designing, implementing and marking formative tests, and these tests are not internally moderated.

Summative tests (examinations) are developed centrally by Subject Sub-Committees. The appointment of subject sub-committee coordinators are done in rotation so that all campuses have a chance to lead these Committees. The term of office is 2 years. The committee members elect a Chair and the Committee is then supported by that campus principal. Once elected, all committee members and coordinators are approved by the Senate. 
They meet and develop examination items or discuss and approve items and marking guides submitted to them from academics on different campuses. Answer guides have to provide references for facts, but it is not clear what the currency of sources is. The subject coordinator then chooses the final items for the examination paper and provides this to the external moderator from the associated University. Required changes are made and then the paper is finalized (Coordinator, moderator and examinations officer) and taken in a secure fashion to the Examinations Clerk. Papers are generated centrally and sent by courier to the different campuses, where they are the responsibility of the principal until handed over to the invigilator on the day of the examination.

In most cases, scripts are marked by more than one examiner in one location. A second internal moderator moderates the marking and then it is sent for external moderation.

With regard to clinical examinations, a person called an "inter-rater marker" is appointed to moderate the marking at all manned stations of Objectively Observed Clinical Examinations (OSCE). The station marker and the inter-rater marker meet after the examination to discuss discrepancies and make written comments on these. These reports then go to the moderator for a final decision.

In some of the programmes, the SA Nursing Council is the examiner for the theoretical papers, although the examinations are written on the College campuses. In these cases, the College has no control over the examinations.

The College has an association agreement with two universities - the University of KwaZulu-Natal and the University of Zululand. Selected academics sit on appropriate Subject Sub-Committees and act as moderators for the examinations of that subject. Moderators are identified by the universities and appointed/approved by Senate. The external moderator provides a moderation report. Moderation reports are discussed at the next Subject Sub-Committee meeting. Curricula are reviewed every second year and changes are recommended to Senate in writing by the Subject Sub-Committees.

Examination results and the moderators' reports go to the Examination Commission in the first instance. The Commission consists of the top managers of the College. They discuss the results, change marks according to policy, make all decisions about passing, failing and exclusion and check all results.

The qualifications for moderators in the nursing subjects are appropriate, but this might be less so in the Biomedical Sciences such as Anatomy and Physiology, since all subjects are moderated by faculty of the School of Nursing at these two universities.

The central College Office has a dedicated Examinations Office, with careful security arrangements, including having their own copying machine, own staff, and safe room. Many specific security arrangements exist; for instance, only the subject coordinator has access to the item bank. A secure process is followed, whereby any examination recorded on the computer of the examiner is then transferred to that of the examination officer and then wiped from the examiner's computer. The examination office limits access and uses internal machines for all work. The College has never had an incident of papers being lost or leaked.

\section{Recommendations:}

6.1 Develop an assessment and moderation policy, including internal moderation

6.2 Review the RPL policy in view of the new qualifications. 
Criterion 7: Infrastructure and library resources: Suitable and sufficient venues, IT infrastructure and library resources are available for students and staff in the programme. Policies ensure the proper management and maintenance of library resources, including support and access for students and staff. Staff development for library personnel takes place on a regular basis

\section{Evaluation: Criterion not met}

Six campuses reported a LAN facility for students. Most campuses have only Intranet and no Internet connection. On about half of the campuses, only 1 telephone line exists, making it impossible to add a tele-teaching service. The majority of campuses (17) do not have an IT technician available.

With regard to the clinical laboratory infrastructure, the condition of the equipment ( 9 sites) and the number of stations ( 6 sites) were the biggest problems with these teaching-learning spaces. Only between 3 and 5 campuses were adequately resourced in terms of these items. In 4 sites the variety of models was insufficient, and in 4 space for the number of students was inadequate.

Although accommodation for students and staff is not part of the HEQC, the field workers looked at these aspects as well. There seems to be a general problem that the student accommodation is inadequate. Many problems were also mentioned with relation to quality of the accommodation:

- No cooking facilities, forcing them to use external food providers;

- No laundry facilities;

- $\quad$ Sharing rooms with up to four per room;

- Male-female placements present a problem;

- $\quad$ Dilapidated buildings and poor maintenance.

While in some cases teaching staff are only accommodated temporarily, in others there are complaints that permanent staff move in and never move out, thus blocking rooms permanently.

At 13 of the campuses a need for staff accommodation was mentioned, even though there is limited staff accommodation already available.

\section{Recommendations:}

7.1 Integrate clinical preceptors into the programme management structure

7.2 Emphasize position of programme coordinator/manager with a clear job description

7.3 Write a policy for generating certificates to protect the College's integrity

\section{Conclusion}

It became evident through the feasibility study that $70-80 \%$ of the KZN CN budget is spent on salaries of staff and students. The implication is that a minimal percentage could have been spent on teaching and learning. Nursing training colleges enjoy no independence with regard to generating income (Geyer 2008: 86). As political puppet-masters, the relevant health authorities control college governance. In the feasibility study, campus staff generally gave the impression that they were not well informed, not in control, and not independent with regard to their own finances.

South African Colleges of Nursing will never be able to adhere to the standards of higher education unless the governance context changes so as to favour the autonomy of these colleges. The biggest challenge lies in adequate funding to ensure quality standards within the college teaching and learning environment. 
The KwaZulu-Natal College has maintained a credible output of nurses since 1986 when its forerunners were established. It has a good reputation and has worked hard to train and educate good nurses and to create a positive learning and working environment. Rapid changes in the health services, shortages, and the high disease burden has not always made this easy. Now the college seems to be entering a new era. It has earned the right to be upgraded to a state fit for its new status as a HEI. An intensive, comprehensive study, as well as wide stakeholder consultation took place before the proposed recommendations were formulated. None of the recommendations are luxuries: they are all prerequisites for a HEI.

The results of the feasibility study are supportive of the multifaceted nature of higher education. Geyer (2008: 89) rightfully states:

The education and training environment is clearly complex and while nursing colleges are situated outside the mainstream of education, these complexities have a major impact on nursing programmes and the quality of these programmes.

In order rightfully to become part of the higher education arena, future college nurse educators are certainly challenged by a complex process to ensure quality within programmes leading to accredited nursing qualifications.

\section{References:}

CHE (Council on Higher Education). 2004. Criteria for Programme Accreditation. Pretoria: CHE.

CHE (Council on Higher education). 2013. A Framework for Qualification Standards in Higher Education. Second Draft. Pretoria: CHE.

FUNDISA (Forum of University Nursing Deans in South Africa). 2011. News November 2011, Preparation of Nurse Specialists by Universities.

http://www.fundisaforum.org/archive.htm

Date of access: 8 April 2013.

FUNDISA (Forum of University Nursing Deans in South Africa). 2012. Report of the Feasibility Study of Kwa-Zulu Natal (KZN) Nursing College. (Unpublished report). Pretoria: FUNDISA.

Geyer, N. \& Vasuthevan, S. 2008. The Formal Education and Training Environment (p78-95). In: Kotze, W. (ed.). 2008. Nurse Educators' Guide to Management, Second ed. Pretoria: Van Schaik.

SANC (South African Nursing Council). 2013a. Details of New Nursing Qualifications. <http://www.sanc.co.za/>

Date of access: 30 April 2013.

SANC (South African Nursing Council). 2013b. New Qualifications: Frequently Asked Questions (FAQs). 
<http://www.sanc.co.za/pdf/New\%20Qualifications\%20FAQs.pdf>

Date of access: 30 April 2013.

RSA (Republic of South Africa). 2008a. Higher Education Amendment Act, No. 39 of 2008. Pretoria: Government Printer.

RSA (Republic of South Africa). 2008b. National Qualifications Framework Act, No. 67 of 2008. Pretoria: Government Printer.

Uys, L.R. \& Gwele, N.S. 2005. Curriculum Development in Nursing. New York: Routledge. 